Article

\title{
Application of the Oriented Fuzzy Numbers in Credit Risk Assessment
}

\author{
Aleksandra Wójcicka-Wójtowicz ${ }^{1, *(\mathbb{D})}$ and Krzysztof Piasecki ${ }^{2}$ (D) \\ 1 Department of Operations Research and Mathematical Economics, Poznań University of Economics and \\ Business, 61-875 Poznań, Poland \\ 2 Institute of Economics and Finance, WSB University in Poznań, 61-895 Poznań, Poland; \\ krzysztof.piasecki@wsb.poznan.pl \\ * Correspondence: aleksandra.wojcicka-wojtowicz@ue.poznan.pl
}

check for updates

Citation: Wójcicka-Wójtowicz, A.; Piasecki, K. Application of the Oriented Fuzzy Numbers in Credit Risk Assessment. Mathematics 2021, 9 , 535. https://doi.org/10.3390/ math9050535

Academic Editor: Antonio Francisco Roldán López de Hierro

Received: 31 January 2021

Accepted: 1 March 2021

Published: 4 March 2021

Publisher's Note: MDPI stays neutral with regard to jurisdictional claims in published maps and institutional affiliations.

Copyright: (c) 2021 by the authors. Licensee MDPI, Basel, Switzerland. This article is an open access article distributed under the terms and conditions of the Creative Commons Attribution (CC BY) license (https:// creativecommons.org/licenses/by/ $4.0 /)$.

\begin{abstract}
Over the years, banks have faced many difficulties, related mainly to lax credit standards for borrowers and counterparties. The goal of credit risk management is to maintain the volume of credit risk at acceptable level as it is a vital feature in risk management. Credit analysts take into consideration factors of a wider spectrum, e.g., the prospects of the line of business, the experience of board members, credibility of suppliers, etc. Those factors are often considered on the linguistic scale, which includes such imprecise and inaccurate phrases, for instance, such as: more/less experienced, better/worse prospects, etc., which, for the experts and decision makers, are justified and result from their personal experience, preferences and human nature. The paper presents the approach of supporting methods in the credit risk decision-making process. It presents evaluation scales of imprecise phrases commonly used during the process of credit risk assessment based on experts' preferences. Due to the imprecision, the oriented fuzzy numbers are a useful tool. For such described evaluation scales, we use a scoring function determined with the use of an adapted Simple Additive Weighting (SAW) method.
\end{abstract}

Keywords: credit risk assessment; SAW method; oriented fuzzy numbers

\section{Introduction}

The correct classification of debtors is an important topic. Therefore, we can encounter new approaches and methods. Those methods, which are to aid the decision makers, are continuously improved to succeed in a better classification of potential banks' clients. International institutions, such as, for instance, Basel Committee on Banking Supervision, recognize the significance of risk management and express their opinion, as well as some guidelines, in published documents. One of those documents is Basel III, which refers specifically to risk management and supervision. In a subsequent forth document, the focus is on a standardized and internal rating-based (IRB) credit risk approach.

The process of a potential debtor assessment is multilayered and therefore must be considered in several steps. The first step would be a scrutinized analysis of financial statements which generally is standardized, followed by classification into a rating class and a recommendation of the risk analyst. Of course, the main foundation is the transparency throughout the whole process to enable further comparisons.

From that stage on, standard numerical methods lose their main significance, leaving the final decision to experts—banks' employees (higher level managers, in some cases also called the "Board").

Experts take the ultimate decision basing on their professional experience. However, in this process, apart from experience, they also involve their ability to project future outcomes of the decision made. It is vital as the financial statements only show the performance in the past. Further, all macroeconomic factors, such as the standing of the debtor's industry, play 
a vital role in determining the future prospects of bank's client and via experts' knowledge can be included in the assessment and directly influence the final decision.

The main objective of the paper focuses on that third part of the process, which refers to experts' own experience and preferences which rarely are expressed in a precise manner. The imprecision and inaccurateness result from a human nature and imprecision of linguistic scales including such terms as: more/less experienced, better/worse prospects, more/less interesting branch of industry, higher/lower expectations of growth, etc.

Therefore, it is important to investigate and recognize the importance of experts' specialized knowledge, experience and preferences in the implementation of fuzzy techniques to aid the assessment of loan and credit applicants (borrowers). Fuzzy logic is regarded as one of the most efficient methods to assist control systems. It is due to the fact that it resembles the decision-making process of a human which, in turn, enables reaching the conclusion (decision) basing on imprecise or, what is even more important, approximate information. It also fills the gap between purely mathematical and logic-based approaches in management.

The concept of a fuzzy number (FN) is a commonly accepted model of an imprecise number. The notion of an ordered FN is intuitively introduced by Kosiński and his cowriters [1] as such model of an imprecise number and its arithmetic that a subtraction is the inverse operator to addition. For formal reasons, the Kosiński's theory was revised in [2]. In this way, we get oriented FNs (OFNs). We see that OFNs application is a quite new fuzzy technique. Therefore, the main aim of our paper is the application of OFNs for a real problem of potential debtors' classification. We here test the suitability of OFNs for determining the numerical order scale used for scoring function implemented for credit risk management.

Our paper is organized in the following way. Section 2 presents the general concepts of fuzzy systems. In this context, we briefly discuss a literature devoted to the problem of application fuzzy techniques for credit risk management. Section 3 briefly describes the idea of OFN in some simplified case. Arithmetic operators for this case are introduced. In Section 4, the linguistic order scale is presented. The concept of numerical order scale is introduced here. The Simple Additive Weighting (SAW) Method implemented for credit risk management is described in Section 5. In Section 6, the authors present results of a case study devoted to the real problem of potential debtors' classification. Finally, Section 7 concludes the article, summarizes the main findings of this research and proposes some future directions of investigation.

\section{Foundations of Fuzzy Systems}

Among the methods that have been supporting the process of credit risk assessment so far, we can list such methods as: scoring methods, discriminant analysis, rating methods, decision tree, standard models, reduced models, IRB approach, neural networks, etc.

However, due to the common imprecision of linguistic expressions used by the experts (decision makers), the fuzzy sets techniques can be used to help to systemize and classify potential debtors. Therefore, a method that can combine imprecise or inaccurate information and the experience of experts is an efficient solution to execute risk analysis in various domains for complicated systems. In such cases, a combination of fuzzy sets theory and a linguistic approach proves to be very helpful.

Zadeh, who is recognized as a founder of the fuzzy set theory, described fuzzy sets as a class of objects whose memberships were not precisely defined [3], and due to that characteristic, they are considered to provide a better representation of reality than strictly quantitative methods. Further, in [4], the embedded imprecision of natural languages was thought to be more possibilistic than probabilistic. According to this hypothesis it was suggested that a problem expressed in natural language can be presented as a technique that calculates the probability distribution of a set of various characteristics which are implied by utilizing the idea of possibility distribution. Furthermore, in [4], a theory of possibility was described. It connects the theory of possibility and fuzzy sets via the 
definition of a possibility distribution presented as a fuzzy constraint which operates as a flexible restriction on indicated values linked to an individual variable.

Many researchers followed Zadeh's line of thinking; however, the results of their work did not always support each and every aspect of Zadeh's approach. For instance, in [5], some methods of making fuzzy decisions were reviewed. The main idea was to define a space in which fuzzy sets were embedded and, furthermore, to juxtapose the variations (different sets) against one another and describe the whole procedure in a different manner. It was believed to overcome the shortcomings of other methods.

In $[6,7]$, we can find a review of various approaches of operations used in fuzzy sets theory, as well as formal approaches based on different intuitions. In [8], basic notions underlying fuzzy sets, especially concerning such measures as gradualness, uncertainty, vagueness and bipolarity, were discussed to determine the importance of fuzzy sets practical utility. In turn, new similarity measures that were supposed to define the measures of similarity of fuzzy sets and elements were further discussed in [9].

When it comes to the above mentioned combination of fuzzy sets and linguistic operators, in [10], the concept of construction project analysis using fuzzy methodology was presented. Moreover, the methodology of risk evaluation with the use of linguistic approach was discussed. It provided the analyst with the ability to indicate the levels of risk of each individual element of the project and pass it to recipients in a form of widely-understood phrases. Further, in [11], the linguistic approach is applied in a form of operators coming from decision and fuzzy-sets theory. A fuzzy logic model was also used for credit risk rating in [12]. A fuzzy classification method for credit risk in banking system was implemented in [13]. This implementation was based on fuzzy rules used to assess similarity of objects. Moreover, a membership degree was utilized for characteristics in relation to each given option. The aim of the research described in [14] was to overcome the limitations of methods which, with the aid of econometrics and fuzzy logic approach, computed the creditworthiness and probability of default of a potential borrower. Other possibilities for fuzzy methods application in credit risk assessment were presented in [15]. An experiment of creating and implementing a developed Expert Fuzzy System to assess credit risk according to specified effective financial ratios as the system inputs was proposed in [16]. Another fuzzy logic prediction system for credit risk assessment was shown in [17]. In this research, the author, basing on the obtained results, concludes that the fact that fuzzy set theory allows for including unavoidable imprecision in the data records, results in a promising solution to credit risk analysis and other prediction problems.

In [18], it was presented how fuzzy logic with linguistic quantifiers can be used in group decision making. This technique bases on the approach that fuzzy linguistic quantifiers can identify a fuzzy majority which might be the nearest approximation of a human assessment of the very fundamental nature of majority. Authors come to the conclusion that fuzzy logic offers instruments of a formal procedure for fuzzy majority-which, with the use of classical approach, was impossible. It was also mentioned in [19] that the main objective of linguistic models based on the general theory of fuzzy sets is to examine linguistic data statistically, to classify the data based on patterns found and to extract knowledge that is operational from the point of view of some other objectives. The conclusions were that classic taxonomic algorithms might be successful in classifying debtors; however, their results can be enhanced with the use of linguistic data transformation. In [20], an example of a hybrid fuzzy approach is presented in a form of a fuzzy classifier for contractor default prediction (FICDP), which focuses on decreasing the risk of insolvency resulting from the wrong classification of contractors.

\section{Oriented Fuzzy Numbers}

In a predefined space $X$, we can place any object of considerations simply as its element. An elementary instrument when considering an imprecise categorization of those objects 
is the concept of fuzzy sets presented in [3]. A its membership function $\mu_{A} \in[0,1]^{\mathbb{X}}$ can unambiguously determine any fuzzy set $A$ in the following manner:

$$
\mathcal{A}=\left\{\left(x, \mu_{A}(x)\right) ; x \in \mathbb{X}\right\}
$$

From the perspective of multi-valued logic [21], we can interpret a value $\mu_{A}(x)$ as a

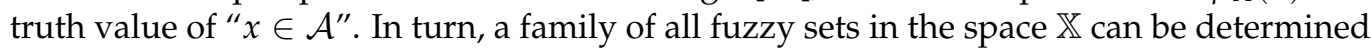
by $\mathcal{F}(\mathbb{X})$. The main idea in [22] is to present the imprecise approximation of a real number as a fuzzy number (FN).

In [23], we can find the intuitive introduction of ordered FNs. They were presented as a FNs extension. The reason behind the effectiveness of ordered FNs comes from the interpretation of FNs that includes additional knowledge about the position of the estimated number. Presently, ordered FNs introduced by Kosiński are usually called Kosiński's numbers [24-27]. A wide analysis and debate on the existing state-of-art on Kosiński's numbers can be found in [28]. However, a major disadvantage of Kosiński's theory appears to be the existence of such Kosiński's numbers that are not FNs1. The revision of Kosiński's theory can be found in [2]. If ordered FN is defined using the reviewed characterization, then it is known as an Oriented FN (OFN). Any imprecise number, provided with the additional information about the position of the number being approximated, is described by OFN. It must be stressed that the OFN definition of the latter fully relates to the intuitive definition of Kosiński's numbers.

Further elaboration will be restricted to Trapezoidal OFNs (TrOFN) defined as fuzzy subsets in the space $\mathbb{R}$ of all real numbers according to Definition 1.

Definition 1 ([2]). For any monotonic sequence $(a, b, c, d) \subset \mathbb{R}, \operatorname{TrOFN} \stackrel{\leftrightarrow}{\operatorname{Tr}}(a, b, c, d)=\stackrel{\leftrightarrow}{T}$ is the pair of the orientation $\overrightarrow{a, d}=(a, d)$ and a fuzzy subset $\mathcal{T} \in \mathcal{F}(\mathbb{R})$ determined explicitly by its membership functions $\mu_{T} \in[0,1]^{\mathbb{R}}$ as follows

$$
\mu_{T}(x)=\mu_{T r}(x \mid a, b, c, d)=\left\{\begin{array}{cc}
0, & x \in[\min \{a, d\}, \max \{a, d\}], \\
\frac{x-a}{b-a}, & x \in[\min \{a, b\}, \max \{a, b\}], \\
1, & x \in[\min \{b, c\}, \max \{b, c\}], \\
\frac{x-d}{c-d}, & x \in[\min \{c, d\}, \max \{c, d\}],
\end{array}\right.
$$

The adjective "trapezoidal" reflects the fact that the chart of any TrOFN membership function is of a trapezoidal shape. The symbol $\mathbb{K}_{T r}$ refers to a space of all TrOFNs. It is the orientation of OFN that provides that information. If $a<d$ then $\operatorname{TrOFN} \overleftrightarrow{\operatorname{Tr}}(a, b, c, d)$ is of a positive orientation $\vec{a}, \vec{d}$. For any $z \in[b, c], \operatorname{TrOFN} \stackrel{\leftrightarrow}{\operatorname{Tr}}(a, b, c, d)$ which is positively oriented is a formal model of linguistic variable "about or slightly above $z$ ". If $a>d$, then TrOFN $\overleftrightarrow{\operatorname{Tr}}(a, b, c, d)$ is of a negative orientation $\overrightarrow{a, d}$. For any $z \in[c, b], \operatorname{TrOFN} \overleftrightarrow{\operatorname{Tr}}(a, b, c, d)$ which is negatively oriented is a formal model of linguistic variable "about or slightly below $z$ ". Comprehension of the above mentioned sentences "about or slightly above $z$ " and "about or slightly below $z^{\prime \prime}$ is determined by the employed semantics of the natural language. If $a=d$, then $\operatorname{TrOFN} \stackrel{\leftrightarrow}{\operatorname{Tr}}(a, a, a, a)=\llbracket a \rrbracket$ defines unoriented real number $a \in \mathbb{R}$.

By restricting ourselves to TrOFN, we will be able to simplify the applied arithmetic operations. It is a practice used by many researchers. The arithmetic operators of dot product $\odot$ for TrOFNs were presented by Kosiński as follows:

$$
\odot \overleftrightarrow{\operatorname{Tr}}(a, b, c, d)=\overleftrightarrow{\operatorname{Tr}}(\beta \cdot a, \beta \cdot b, \beta \cdot c, \beta \cdot d)
$$

In [2], the sum $\boxplus$ for TrOFNs is introduced as follows

$$
\overleftrightarrow{\operatorname{Tr}}(a, b, c, d) \boxplus \overleftrightarrow{\operatorname{Tr}}(p-a, q-b, r-c, s-d)= \begin{cases}\overleftrightarrow{\operatorname{Tr}}(\min \{p, q\}, q, r, \max \{r, s\}) & (q<r) \vee(q=r \wedge p \leq s) \\ \overleftrightarrow{\operatorname{Tr}}(\max \{p, q\}, q, r, \min \{r, s\}) & (q>r) \vee(q=r \wedge p>s)\end{cases}
$$


Let us take into account a pair $(\overleftrightarrow{\mathcal{K}}, \stackrel{\leftrightarrow}{\mathcal{L}}) \in \mathbb{K}_{T r}^{2}$ characterized by a pair $\left(\mu_{K}, \mu_{L}\right) \in$

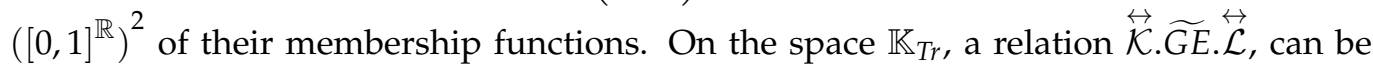
introduced which translates into:

$$
\text { "TrOFN } \overleftrightarrow{\mathcal{K}} \text { is greater than or equal to } \operatorname{TrOFN} \stackrel{\leftrightarrow}{\mathcal{L}} \text {." }
$$

The above relation is a fuzzy pre-order $\widetilde{G E} \in \mathcal{F}\left(\mathbb{K}_{T r}^{2}\right)$. It is explained by its membership function $v_{G E} \in[0,1]^{\mathbb{K}_{T r}^{2}}[27,28]$. From the perspective of multi-valued logic, we can interpret a value $v_{G E}(\overleftrightarrow{\mathcal{K}}, \overleftrightarrow{\mathcal{L}})$ as a truth value of (6). In [27], it is shown that for any pair $(\operatorname{Tr}(a, b, c, d), \operatorname{Tr}(e, f, g, h)) \in \mathbb{K}_{T r}^{2}$ we have

$$
v_{G E}(\overleftrightarrow{\operatorname{Tr}}(a, b, c, d), \stackrel{\leftrightarrow}{\operatorname{Tr}}(e, f, g, h))=\left\{\begin{array}{cc}
0, & 0<\alpha-\gamma \\
\frac{\alpha-\gamma}{\alpha+\delta-\beta-\gamma}, & \alpha-\gamma \leq 0<\beta-\delta \\
1, & \beta-\delta \leq 0
\end{array}\right.
$$

where,

$$
\begin{aligned}
& \alpha=\max \{a, d\} \\
& \beta=\max \{b, c\} \\
& \gamma=\min \{e, h\} \\
& \delta=\min \{f, g\}
\end{aligned}
$$

Therefore, for any pair $(\operatorname{Tr}(a, b, c, d), \llbracket e \rrbracket) \in \mathbb{K}_{T r} \times \mathbb{R} \subset \mathbb{K}_{T r}^{2}$ we get

$$
v_{G E}(\stackrel{\leftrightarrow}{\operatorname{Tr}}(a, b, c, d), \llbracket e \rrbracket)=\left\{\begin{array}{cl}
\max \{a, d\}<e, \\
\frac{\max \{a, d\}-e}{\max \{a, d\}-\max \{b, c\}}, & \max \{a, d\} \geq e>\max \{b, c\}, \\
1, & 0 \leq c-f .
\end{array}\right.
$$

\section{Linguistic Method-Basic Facts}

We can assume that any characteristics of a potential debtor can be presented in a quantitative manner that will provide us with an estimation regarded as an imprecise information. Consequently, in such situation it is advised to implement a linguistic approach as an alternative to a quantitative solution. This introduces a more adaptable approach that sufficiently enables a direct and precise representation of imprecise information and [29]. Hence, a problem of transforming qualitative data into numerical characteristics is averted.

At an initial level of implementing the linguistic technique it is vital to define the imprecision granularity-for instance the number of terms used for expression of the information - which determines the ability to distinguish various expressions among one another. If the imprecision granularity rises, the knowledge values also increase. Usually, it is customarily accepted that the cardinality should be an odd number, in the range of 3 to 13. It is important to stress that the concept of granular computing is presented in [30], where it is compared to human ability to come up with a solution and decision basing it on imprecise information and only partial truth, certainty and knowledge. Furthermore, in [31] it is highlighted that the concept of granularity comes from practical requirements leading to simple, clear and low cost estimates.

In general we can quote after [29] that any linguistic value can be described with the aid of individual labels burdened with a specific semantic value. The label can be defined as an individual part of a whole linguistic set. Eventually, an apparatus to establishing linguistic characteristics can be arranged. 
In the presented model of debtors' classification, the linguistic labels refer to Tentative Order Scale (TOS). TOS can be given as a follows

$$
\text { TOS }=\{\text { Bad, Average, Good }\}=\{C, B, A\}=\left\{V_{1}, V_{2}, V_{3}\right\}
$$

Each element of TOS is called a reference point and it can be expanded by additional orientation expressions:

- "much below" indicated as "- -",

- "below" indicated as "_",

- "around" indicated as " $\sim$ ",

- "above" indicated as "+",

- "much above" indicated as " ++ ".

For the first time, to determine the linguistic labels of an order scale, the rating terminology used by credit risk analysts was utilized. The outcome of each label is a combination of a reference point and orientation phrase. Such representation is called an Extended Order Scale (EOS) [32]. Also for the first time, EOS with two-stage orientation phrases was used. In [27,32], only one-stage orientation phrases were utilized.

In information studies, any word derived from natural language is believed to be a linguistic variable determined as a fuzzy subset in space $X$. Then, those variables are converted with the use of fuzzy set theory [33-35]. The review on linguistic variable conversion and popular methodologies, in the field of decision making, can be found in $[29,36,37]$.

We can determine a reference point represented by the number $j \in \mathbb{N}$ as $V_{j}$. On the other hand, we must still remember that the semantic meaning of any orientation expression is not precise. Therefore, we can consider any order label to be an imprecise approximation of the reference point. For this reason, any order label resulting from utilized EOS must be denoted in the real line $\mathbb{R}$ by some kind of FNs [38]. To facilitate further implementation, the restriction to represent the characteristics by TrFNs can always be added. Additionally, an observation has been made that the orientation of fuzzy numbers referring to an approximated reference point are determined by the orientation characteristics; hence, TrOFNs can also represent any order label. This method is more realistic and accurate than representing order labels by trapezoidal fuzzy numbers. Then again, the exclusion of information on orientation of order labels can cause an unreliable appraisal of potential debtor [39]. Thus, in the paper TrOFNs will represent all order labels. We call the family of all TrOFNs, which represent the above mentioned EOS, Numerical Order Scale (NOS). The essence of processing any EOS lies in attributing it with an adequate NOS. Here, for the first time, such a specific NOS was implemented, which was adjusted to both TOS and EOS with a two-stage orientation phrase.

All applied order scales (TOS, EOS, NOS), proposed for credit risk assessmentdebtors' classification, are presented in Table 1.

Table 1. Order scales.

\begin{tabular}{|c|c|c|c|}
\hline TOS & EOS & Semantic Meaning & NOS \\
\hline \multirow{5}{*}{ C } & $C--$ & much below Bad & $\overleftrightarrow{\operatorname{Tr}}\left(1,1, \frac{3}{4}, \frac{1}{4}\right)$ \\
\hline & $C-$ & below Bad & $\overleftrightarrow{\operatorname{Tr}}\left(\frac{5}{4}, 1, \frac{3}{4}, \frac{2}{4}\right)$ \\
\hline & $C \sim$ & around Bad & $\stackrel{\leftrightarrow}{\operatorname{Tr}}\left(\frac{2}{4}, 1,1, \frac{6}{4}\right)$ \\
\hline & & Bad & $\stackrel{\leftrightarrow}{\operatorname{Tr}}(1,1,1,1)$ \\
\hline & $C+$ & above Bad & $\overleftrightarrow{\operatorname{Tr}}\left(\frac{3}{4}, 1, \frac{5}{4}, \frac{6}{4}\right)$ \\
\hline
\end{tabular}


Table 1. Cont.

\begin{tabular}{|c|c|c|c|}
\hline TOS & EOS & Semantic Meaning & NOS \\
\hline \multirow{8}{*}{$B$} & $C++$ & much above Bad & $\overleftrightarrow{\operatorname{Tr}}\left(1,1, \frac{5}{4}, \frac{7}{4}\right)$ \\
\hline & $B--$ & much below Average & $\overleftrightarrow{\operatorname{Tr}}\left(2,2, \frac{7}{4}, \frac{5}{4}\right)$ \\
\hline & $B-$ & below Average & $\overleftrightarrow{\operatorname{Tr}}\left(\frac{9}{4}, 2, \frac{7}{4}, \frac{6}{4}\right)$ \\
\hline & $B \sim$ & around Average & $\overleftrightarrow{\operatorname{Tr}}\left(\frac{6}{4}, 2,2, \frac{10}{4}\right)$ \\
\hline & & Average & $\overleftrightarrow{\operatorname{Tr}}(2,2,2,2)$ \\
\hline & $B+$ & above Average & $\stackrel{\leftrightarrow}{\operatorname{Tr}}\left(\frac{7}{4}, 2, \frac{9}{4}, \frac{10}{4}\right)$ \\
\hline & $B++$ & much above Average & $\overleftrightarrow{\operatorname{Tr}}\left(2,2, \frac{9}{4}, \frac{11}{4}\right)$ \\
\hline & $A--$ & much below Good & $\overleftrightarrow{\operatorname{Tr}}\left(3,3, \frac{11}{4}, \frac{9}{4}\right)$ \\
\hline \multirow{5}{*}{$A$} & $A-$ & below Good & $\overleftrightarrow{\operatorname{Tr}}\left(\frac{13}{4}, 3, \frac{11}{4}, \frac{10}{4}\right)$ \\
\hline & $A \sim$ & around Good & $\overleftrightarrow{\operatorname{Tr}}\left(\frac{10}{4}, 3,3, \frac{14}{4}\right)$ \\
\hline & & Good & $\overleftrightarrow{\operatorname{Tr}}(3,3,3,3)$ \\
\hline & $A+$ & above Good & $\overleftrightarrow{\operatorname{Tr}}\left(\frac{11}{4}, 3, \frac{13}{4}, \frac{14}{4}\right)$ \\
\hline & $A++$ & much above Good & $\overleftrightarrow{\operatorname{Tr}}\left(3,3, \frac{13}{4}, \frac{15}{4}\right)$ \\
\hline
\end{tabular}

Orientation of TrOFN included in NOS is closely correlated with the orientation phrase extending TOS to EOS.

\section{Simple Additive Weighting Method}

The evaluation template of borrowers distinguishes all characteristics that are assessed. A potential debtor can be assessed with the use of a chosen scoring function that includes preferences of experts regarding all attributes and their significance. A procedure of defining the assessment template is a vital part of credit risk evaluation. It also concerns creating the scoring function, which is utilized in the time prior to an evaluation or negotiation. The debtors are frequently described by several opposing characteristics and hence the multi-criteria methods are suitable for creating the scoring function. One of the most widely used methods in multi-criteria assessment is the Simple Additive Weighting (SAW) method $[38,40]$.

SAW method belongs to a group of scoring techniques which base on the idea of a weighted average of individual criterion ratings. When it comes to classification of borrowers, the ratings are described by TrOFNs. Due to that fact SAW needs to be combined with TrOFNs, the combined SAW method must be equipped with a scoring function defined on the space $\mathbb{K}_{T r}^{n}=\mathbb{K} \times \mathbb{K} \times \ldots \times \mathbb{K}$.

The SAW method was first introduced in [38]. Due to its properties, the descriptive name for SAW method is sometimes Simple Multi Attribute Rating Technique [41].

In [42], we can find an introduction of a fuzzy SAW method that uses ratings described by fuzzy numbers. Furthermore, the Oriented Fuzzy SAW (OF-SAW) that applies criterion ratings determined by trapezoidal Kosiński's numbers was initially introduced in [43]. However, in [32], that method was adapted so that it is consistent with the revised approach of OFNs [2]; therefore, the ratings are determined by Trapezoidal OFNs. Below, we adapt the OF-SAW method to the requirements of the assessment of an individual potential debtor.

Our intention is to assess the potential debtor described by characteristics $\mathcal{A} \in \mathbb{A}$ where $\mathbb{A}$ is an expected set of borrowers. In such approach, OF-SAW method can be illustrated as follows:

1. Determine a multi-criteria assessment case by criteria set $\mathbb{D}=\left\{\mathcal{C}_{1}, \mathcal{C}_{2}, \ldots, \mathcal{C}_{n}\right\}$.

2. Define a vector of weights

$$
w=\left(w_{1}, w_{2}, \ldots, w_{n}\right) \in\left(\mathbb{R}_{0}^{+}\right)^{n}
$$


where,

$$
w_{1}+w_{2}+\ldots+w_{n}=1
$$

and $w_{j}$ is the weight of the criterion $\mathcal{C}_{j}$ describing the significance of particular criterion in a studied assessment problem.

3. Determine the scope $Y_{j}$ for an individual characteristic $\mathcal{C}_{j}(j=1,2, \ldots, n)$.

4. Establish an assessment template.

$$
\mathbb{Y}=Y_{1} \times Y_{2} \times \ldots \times Y_{n} \supset \mathbb{A}
$$

5. Determine NOS $\mathbb{O} \subset \mathbb{K}_{t r}$.

6. Determine the assessment function $\mathcal{X}: \mathbb{Y} \times \mathbb{D} \rightarrow \mathbb{O} \subset \mathbb{K}_{t r}$ so that the value $\mathcal{X}\left(\mathcal{A}, \mathcal{C}_{j}\right) \in$ $\mathbb{( O}$ equals the assessment of characteristics record $\mathcal{A}$ from the perspective of a criterion $\mathcal{C}_{j}(j=1,2, \ldots, n)$.

7. Establish a scoring function $S \overleftrightarrow{A} W: \mathbb{Y} \rightarrow \mathbb{K}_{\operatorname{Tr}}$ given for any $\mathcal{A} \in \mathbb{Y}$ by the identity

$$
S \overleftrightarrow{A} W(\mathcal{A})=\left(w_{1} \odot \mathcal{X}\left(\mathcal{A}, \mathcal{C}_{1}\right)\right) \boxplus\left(w_{2} \odot \mathcal{X}\left(\mathcal{A}, \mathcal{C}_{2}\right)\right) \boxplus \ldots \boxplus\left(w_{n} \odot \mathcal{X}\left(\mathcal{A}, \mathcal{C}_{n}\right)\right)
$$

For a defined assessment template $\mathbb{Y}$, the standard scoring method of debtors' evaluation may be determined as a couple $(f, L)[44,45]$ :

- $f: \mathbb{Y} \rightarrow \mathbb{R}$ is a defined scoring function,

- $L \in \mathbb{R}$ is a pre-established degree of acceptance of a loan application.

Let us study a loan application of a potential debtor described by characteristics record $\mathcal{A} \in \mathbb{A}$. The application will be acceptable if the condition below is satisfied

$$
f(\mathcal{A}) \geq L
$$

To evaluate the solvency of the potential debtor we propose to use a scoring function $S \overleftrightarrow{A} W: \mathbb{Y} \rightarrow \mathbb{K}_{T r}$. Thus, we recommend transforming the inequality (17) as follows

$$
S \overleftrightarrow{A W}(\mathcal{A}) \cdot \widetilde{G E} \cdot \llbracket L \rrbracket
$$

If (18) is satisfied, it is equal to a following statement:

\section{Credit application based on attributes record $\mathcal{A}$ is acceptable}

Subsequently, the value $v_{G E}(S \stackrel{\leftrightarrow}{A} W(\mathcal{A}), \llbracket L \rrbracket)$ is truth-value of the sentence (19). Therefore, $v_{G E}(S \overleftrightarrow{A} W(\mathcal{A}), \llbracket L \rrbracket)$ can be interpreted as a degree to which the analyzed loan application can be accepted. Hence, we get

$$
\operatorname{accept}(\mathcal{A}, L)=v_{G E}(S \overleftrightarrow{A} W(\mathcal{A}), \llbracket L \rrbracket)
$$

which we call the degree of acceptance. The obtained result may be a significant foundation for the experts when making the ultimate decision regarding the financing.

\section{Results}

In this paper, we apply 12 positive, soft (qualitative) indicators describing a suitable potential borrowers amid the examined. It is in contrast to previous research $[46,47]$ in which 16 criteria were implemented. This change is due to the ongoing process of surveying experts' preferences. The data was collected from experts in the banking field, who are active members of Credit Risk Committees. In an early phase of the study, the most 
significant moment is the determination of qualitative criteria, further used to evaluate the borrower. This is achieved by the utilization of experts' knowledge and preferences. In the study, after the initial struggle, the experts finally determined 12 soft (qualitative) characteristics that can affect the decision. The selected characteristics are shown in Table 2. As there are 12 chosen criteria, the applied individual weighs are $\frac{1}{12}$. Moreover, "a middle point between reference points 'Average' and 'Good'" represents an acceptance level and is denoted as follows

$$
L=\frac{1}{2} \cdot(2+3)=\frac{5}{2}
$$

Table 2. Experts' evaluation of attributes of a construction company.

\begin{tabular}{|c|c|c|c|c|c|c|c|c|c|}
\hline \multirow[t]{2}{*}{ No. } & \multirow[t]{2}{*}{ Criteria } & \multicolumn{2}{|c|}{ Expert 1} & \multicolumn{2}{|c|}{ Expert 2} & \multicolumn{2}{|c|}{ Expert 3} & \multicolumn{2}{|c|}{ Expert 4} \\
\hline & & EOS & NOS & EOS & NOS & EOS & NOS & EOS & NOS \\
\hline 1 & $\begin{array}{l}\text { prospects of } \\
\text { business }\end{array}$ & $\mathrm{C}+$ & $\stackrel{\leftrightarrow}{\operatorname{Tr}}\left(\frac{3}{4}, 1, \frac{5}{4}, \frac{6}{4}\right)$ & B+ & $\stackrel{\leftrightarrow}{\operatorname{Tr}}\left(\frac{7}{4}, 2, \frac{9}{4}, \frac{10}{4}\right)$ & $\mathrm{B}+$ & $\stackrel{\leftrightarrow}{\operatorname{Tr}}\left(\frac{7}{4}, 2, \frac{9}{4}, \frac{10}{4}\right)$ & $\mathrm{A} \sim$ & $\stackrel{\leftrightarrow}{\operatorname{Tr}}\left(\frac{10}{4}, 3,3, \frac{14}{4}\right)$ \\
\hline 2 & $\begin{array}{l}\text { Board members- } \\
\text { experience }\end{array}$ & $\mathrm{A}++$ & $\overleftrightarrow{\operatorname{Tr}}\left(3,3, \frac{13}{4}, \frac{15}{4}\right)$ & $\mathrm{C}++$ & $\overleftrightarrow{\operatorname{Tr}}\left(1,1, \frac{5}{4}, \frac{7}{4}\right)$ & $\mathrm{C}+$ & $\overleftrightarrow{\operatorname{Tr}}\left(\frac{3}{4}, 1, \frac{5}{4}, \frac{6}{4}\right)$ & $\mathrm{A}++$ & $\overleftrightarrow{\operatorname{Tr}}\left(3,3, \frac{13}{4}, \frac{15}{4}\right)$ \\
\hline 3 & $\begin{array}{c}\text { chairperson- } \\
\text { experience }\end{array}$ & $\mathrm{A}++$ & $\overleftrightarrow{\operatorname{Tr}}\left(3,3, \frac{13}{4}, \frac{15}{4}\right)$ & $\mathrm{B}++$ & $\stackrel{\leftrightarrow}{\operatorname{Tr}}\left(2,2, \frac{9}{4}, \frac{11}{4}\right)$ & A+ & $\overleftrightarrow{\operatorname{Tr}}\left(\frac{11}{4}, 3, \frac{13}{4}, \frac{14}{4}\right)$ & $\mathrm{C}++$ & $\stackrel{\leftrightarrow}{\operatorname{Tr}}\left(1,1, \frac{5}{4}, \frac{7}{4}\right)$ \\
\hline 4 & $\begin{array}{l}\text { operations } \\
\text { range—regional }\end{array}$ & $\mathrm{C}+$ & $\overleftrightarrow{\operatorname{Tr}}\left(\frac{3}{4}, 1, \frac{5}{4}, \frac{6}{4}\right)$ & A- & $\overleftrightarrow{\operatorname{Tr}}\left(\frac{13}{4}, 3, \frac{11}{4}, \frac{10}{4}\right)$ & B & $\stackrel{\leftrightarrow}{\operatorname{Tr}}(2,2,2,2)$ & B- & $\stackrel{\leftrightarrow}{\operatorname{Tr}}\left(\frac{9}{4}, 2, \frac{7}{4}, \frac{6}{4}\right)$ \\
\hline 5 & $\begin{array}{l}\text { operations } \\
\text { range-- } \\
\text { international }\end{array}$ & $\mathrm{A}--$ & $\overleftrightarrow{\operatorname{Tr}}\left(3,3, \frac{11}{4}, \frac{9}{4}\right)$ & $\mathrm{C}++$ & $\stackrel{\leftrightarrow}{\operatorname{Tr}}\left(1,1, \frac{5}{4}, \frac{7}{4}\right)$ & B & $\overleftrightarrow{\operatorname{Tr}}(2,2,2,2)$ & $\mathrm{C}_{++}$ & $\overleftrightarrow{\operatorname{Tr}}\left(1,1, \frac{5}{4}, \frac{7}{4}\right)$ \\
\hline 6 & $\begin{array}{l}\text { risk associated } \\
\text { with market }\end{array}$ & $\mathrm{B}++$ & $\overleftrightarrow{\operatorname{Tr}}\left(2,2, \frac{9}{4}, \frac{11}{4}\right)$ & B & $\overleftrightarrow{\operatorname{Tr}}(2,2,2,2)$ & C & $\overleftrightarrow{\operatorname{Tr}}(1,1,1,1)$ & A & $\overleftrightarrow{\operatorname{Tr}}(3,3,3,3)$ \\
\hline 7 & $\begin{array}{l}\text { risk associated } \\
\text { with trade }\end{array}$ & $\mathrm{B}+$ & $\overleftrightarrow{\operatorname{Tr}}\left(\frac{7}{4}, 2, \frac{9}{4}, \frac{10}{4}\right)$ & B & $\stackrel{\leftrightarrow}{\operatorname{Tr}}(2,2,2,2)$ & $\mathrm{C} \sim$ & $\stackrel{\leftrightarrow}{\operatorname{Tr}}\left(\frac{2}{4}, 1,1, \frac{6}{4}\right)$ & A & $\stackrel{\leftrightarrow}{\operatorname{Tr}}(3,3,3,3)$ \\
\hline 8 & $\begin{array}{l}\text { risk associated } \\
\text { with suppliers }\end{array}$ & A- & $\overleftrightarrow{\operatorname{Tr}}\left(\frac{13}{4}, 3, \frac{11}{4}, \frac{10}{4}\right)$ & A+ & $\stackrel{\leftrightarrow}{\operatorname{Tr}}\left(\frac{11}{4}, 3, \frac{13}{4}, \frac{14}{4}\right)$ & $\mathrm{C}++$ & $\overleftrightarrow{\operatorname{Tr}}\left(1,1, \frac{5}{4}, \frac{7}{4}\right)$ & A & $\overleftrightarrow{\operatorname{Tr}}(3,3,3,3)$ \\
\hline 9 & $\begin{array}{l}\text { risk associated } \\
\text { with customers }\end{array}$ & A- & $\overleftrightarrow{\operatorname{Tr}}\left(\frac{13}{4}, 3, \frac{11}{4}, \frac{10}{4}\right)$ & B & $\stackrel{\leftrightarrow}{\operatorname{Tr}}(2,2,2,2)$ & A++ & $\stackrel{\leftrightarrow}{\operatorname{Tr}}\left(3,3, \frac{13}{4}, \frac{15}{4}\right)$ & A & $\overleftrightarrow{\operatorname{Tr}}(3,3,3,3)$ \\
\hline 10 & $\begin{array}{l}\text { diversification- } \\
\text { products } \\
\text { diversification- }\end{array}$ & B & $\stackrel{\leftrightarrow}{\operatorname{Tr}}(2,2,2,2)$ & $\mathrm{C}++$ & $\stackrel{\leftrightarrow}{\operatorname{Tr}}\left(1,1, \frac{5}{4}, \frac{7}{4}\right)$ & $\mathrm{B}++$ & $\overleftrightarrow{\operatorname{Tr}}\left(2,2, \frac{9}{4}, \frac{11}{4}\right)$ & $\mathrm{A}++$ & $\overleftrightarrow{\operatorname{Tr}}\left(3,3, \frac{13}{4}, \frac{15}{4}\right)$ \\
\hline 11 & $\begin{array}{l}\text { sales } \\
\text { markets }\end{array}$ & $\mathrm{C} \sim$ & $\stackrel{\leftrightarrow}{\operatorname{Tr}}\left(\frac{2}{4}, 1,1, \frac{6}{4}\right)$ & B- & $\stackrel{\leftrightarrow}{\operatorname{Tr}}\left(\frac{9}{4}, 2, \frac{7}{4}, \frac{6}{4}\right)$ & $\mathrm{C}+$ & $\stackrel{\leftrightarrow}{\operatorname{Tr}}\left(\frac{3}{4}, 1, \frac{5}{4}, \frac{6}{4}\right)$ & B- & $\stackrel{\leftrightarrow}{\operatorname{Tr}}\left(\frac{9}{4}, 2, \frac{7}{4}, \frac{6}{4}\right)$ \\
\hline 12 & $\begin{array}{l}\text { diversification- } \\
\text { supply } \\
\text { market }\end{array}$ & B & $\overleftrightarrow{\operatorname{Tr}}(2,2,2,2)$ & $\mathrm{B}++$ & $\stackrel{\leftrightarrow}{\operatorname{Tr}}\left(2,2, \frac{9}{4}, \frac{11}{4}\right)$ & A-- & $\overleftrightarrow{\operatorname{Tr}}\left(3,3, \frac{11}{4}, \frac{9}{4}\right)$ & $\mathrm{C}++$ & $\overleftrightarrow{\operatorname{Tr}}\left(1,1, \frac{5}{4}, \frac{7}{4}\right)$ \\
\hline
\end{tabular}

Each expert expresses an opinion related to a particular characteristic with regard to an analyzed enterprises (construction sector). It is achieved by assigning a given criterion a specific grade of EOS, which is then transformed into NOS.

The above table presents results for one company. In total there were five companies analyzed: three from the construction sector, one from the pharmaceutical sector and one from the wholesale business. The choice is not random as those five companies were considered during one session of Credit Committee so we can soundly assume that economic environment was identical for all of them. It is an important factor because even a single factor within a day or week horizon can change or bias experts' attitude to a company in question.

The acquired results indicate that the members of the credit committee often hold opposing or different views on the significance of the soft features when appraising the same company. It is obvious that an individual professional comprehends the criteria in their own way. As a result, we should establish the ultimate appraisal with the aid of mean SAW value indicating a shared opinion of the specialists.

Next, the level of a scoring function SAW (16) for each member of the credit risk committee is calculated. In case of each assessed company, regarding the levels of scoring functions assigned by all specialists, the average level determined by the term Mean SAW is determined. Levels of Mean SAW stand for the opinion articulated by a team of 
experts—not an individual specialist. Table 3 presents levels of individual SAW and Mean SAW.

Table 3. Simple Additive Weighting (SAW) and Mean SAW levels.

\begin{tabular}{|c|c|c|c|c|c|}
\hline \multirow{2}{*}{ Enterprise } & \multicolumn{4}{|c|}{ SAW } & \multirow{2}{*}{ Mean SAW } \\
\hline & Expert 1 & Expert 2 & Expert 3 & Expert 4 & \\
\hline 1 & $\overleftrightarrow{\operatorname{Tr}}\left(\frac{70}{32}, \frac{72}{32}, \frac{75}{32}, \frac{83}{32}\right)$ & $\overleftrightarrow{\operatorname{Tr}}\left(\frac{132}{64}, \frac{136}{64}, \frac{136}{64}, \frac{144}{64}\right)$ & $\stackrel{\leftrightarrow}{\operatorname{Tr}}\left(\frac{72}{32}, \frac{72}{32}, \frac{75}{32}, \frac{83}{32}\right)$ & $\overleftrightarrow{\operatorname{Tr}}\left(\frac{130}{64}, \frac{132}{64}, \frac{136}{64}, \frac{140}{64}\right)$ & $\overleftrightarrow{\operatorname{Tr}}\left(\frac{127}{128}, \frac{138}{128}, \frac{145}{128}, \frac{156}{64}\right)$ \\
\hline 2 & $\overleftrightarrow{\operatorname{Tr}}\left(\frac{124}{64}, \frac{132}{64}, \frac{144}{64}, \frac{156}{64}\right)$ & $\overleftrightarrow{\operatorname{Tr}}\left(\frac{150}{64}, \frac{150}{64}, \frac{156}{64}, \frac{160}{64}\right)$ & $\overleftrightarrow{\operatorname{Tr}}\left(\frac{126}{64}, \frac{136}{64}, \frac{140}{64}, \frac{148}{64}\right)$ & $\overleftrightarrow{\operatorname{Tr}}\left(\frac{140}{64}, \frac{142}{64}, \frac{142}{64}, \frac{154}{64}\right)$ & $\overleftrightarrow{\operatorname{Tr}}\left(\frac{246}{128}, \frac{266}{128}, \frac{302}{128}, \frac{332}{128}\right)$ \\
\hline 3 & $\stackrel{\leftrightarrow}{\operatorname{Tr}}\left(\frac{132}{64}, \frac{132}{64}, \frac{136}{64}, \frac{146}{64}\right)$ & $\stackrel{\leftrightarrow}{\operatorname{Tr}}\left(\frac{70}{32}, \frac{70}{32}, \frac{76}{32}, \frac{84}{32}\right)$ & $\overleftrightarrow{\operatorname{Tr}}\left(\frac{126}{64}, \frac{136}{64}, \frac{148}{64}, \frac{154}{64}\right)$ & $\overleftrightarrow{\operatorname{Tr}}\left(\frac{154}{64}, \frac{154}{64}, \frac{158}{64}, \frac{162}{64}\right)$ & $\overleftrightarrow{\operatorname{Tr}}\left(\frac{137}{128}, \frac{138}{128}, \frac{143}{128}, \frac{156}{64}\right)$ \\
\hline 4 & $\overleftrightarrow{\operatorname{Tr}}\left(\frac{150}{64}, \frac{152}{64}, \frac{159}{64}, \frac{175}{64}\right)$ & $\overleftrightarrow{\operatorname{Tr}}\left(\frac{124}{64}, \frac{136}{64}, \frac{142}{64}, \frac{154}{64}\right)$ & $\overleftrightarrow{\operatorname{Tr}}\left(\frac{68}{32}, \frac{72}{32}, \frac{74}{32}, \frac{80}{32}\right)$ & $\overleftrightarrow{\operatorname{Tr}}\left(\frac{132}{64}, \frac{132}{64}, \frac{136}{64}, \frac{146}{64}\right)$ & $\overleftrightarrow{\operatorname{Tr}}\left(\frac{267}{128}, \frac{288}{128}, \frac{303}{128}, \frac{331}{128}\right)$ \\
\hline 5 & $\overleftrightarrow{\operatorname{Tr}}\left(\frac{128}{64}, \frac{136}{64}, \frac{144}{64}, \frac{156}{64}\right)$ & $\overleftrightarrow{\operatorname{Tr}}\left(\frac{144}{64}, \frac{152}{64}, \frac{154}{64}, \frac{166}{64}\right)$ & $\overleftrightarrow{\operatorname{Tr}}\left(\frac{132}{64}, \frac{136}{64}, \frac{142}{64}, \frac{156}{64}\right)$ & $\overleftrightarrow{\operatorname{Tr}}\left(\frac{150}{64}, \frac{158}{64}, \frac{160}{64}, \frac{164}{64}\right)$ & $\overleftrightarrow{\operatorname{Tr}}\left(\frac{123}{128}, \frac{135}{128}, \frac{143}{128}, \frac{151}{64}\right)$ \\
\hline
\end{tabular}

The next step involves calculation of the acceptance degree (20). The levels are presented in Table 4.

Table 4. Acceptance degree.

\begin{tabular}{|c|c|c|c|c|c|}
\hline \multirow{2}{*}{ Enterprise } & \multicolumn{4}{|c|}{ SAW } & \multirow{2}{*}{ Mean SAW } \\
\hline & Expert 1 & Expert 2 & Expert 3 & Expert 4 & \\
\hline 1 & 0.4250 & 0.0000 & 0.3750 & 0.0000 & 0.0000 \\
\hline 2 & 0.3850 & 0.0125 & 0.0000 & 0.9375 & 0.6111 \\
\hline 3 & 0.3750 & 0.8750 & 0.5375 & 0.8333 & 0.6677 \\
\hline 4 & 0.0000 & 0.9375 & 0.6411 & 0.0515 & 0.5535 \\
\hline 5 & 0.4330 & 0.0000 & 0.5000 & 0.3450 & 0.0000 \\
\hline
\end{tabular}

The values presented in Table 4 can be translated as follows:

- loan application of Company no. 1 is

$\begin{array}{ll}\circ & \text { barely accepted by Expert } 1 \\ \circ & \text { rejected by Expert } 2 \\ \circ & \text { weakly accepted by Expert } 3 \\ \circ & \text { rejected by Expert } 4 \\ \circ & \text { rejected by the team of experts }\end{array}$

- loan application of Company no. 2 is

$$
\begin{array}{ll}
\circ & \text { barely accepted by Expert } 1 \\
\circ & \text { rejected by Expert } 2 \\
\circ & \text { barely accepted by Expert } 3 \\
\circ & \text { strongly accepted by Expert } 4 \\
\circ & \text { accepted by the team of experts }
\end{array}
$$

- $\quad$ credit application of Enterprise 3 is

$$
\begin{array}{ll}
\circ & \text { barely accepted by Expert } 1 \\
\circ & \text { strongly accepted by Expert } 2 \\
\circ & \text { accepted by Expert } 3 \\
\circ & \text { strongly accepted by Expert } 4 \\
\circ & \text { accepted by the team of experts }
\end{array}
$$

and so on for remaining companies. Ultimate decisions regarding accepting or rejecting loan application belong to the members of a credit risk committee. They can support their decision basing on and taking into account the above given results. 


\section{Discussion}

Classification of potential debtors is typically a complicated procedure. It involves many phases and numerous analyzed characteristics. The difference between a potentially creditworthy and potentially insolvent borrower and subsequent acceptance or rejection of non-prospective debtors is a fundamental decision for the creditor. Taking the wrong decision can have a considerable impact on the quality of creditor's portfolio and, in the worst case scenario, lead to bankruptcy. Additionally, a correct classification of possible options is also a crucial element of the decision management process. The imprecision that results from the implementation of linguistic approach (experience of experts expressed in natural language) brings us closer to an intuitive decision-making process. Human ability to perceive nuances, impossible to quantify and putting into strict frames, makes quantitative methods useless. Therefore, a strong need to describe the imprecision resulting from the shortage of an unambiguous quantitative suggestion for just one option amidst a number of possibilities, along with the absence of specific difference between suggested and vetoed options, leads us to fuzzy methods.

In the paper, it was demonstrated that there exists an efficient way to utilize $\operatorname{TrOFN}$ in the process of the assessment of the credit standing of the potential borrower (applicant). This was proven by proposing NOS consisting of TrOFN. This approach originated from and was justified by the necessity of a faithful reflection of a frequently used verbal assessment and its semantic meaning.

It should be stressed that the efficiency consists also of the opportunity to illustrate the deviation of experts' assessment from TOS, basing on the number's orientation. The orientation of TrOFN included in NOS is closely correlated with the orientation phrase extending TOS to EOS. In case of implementation of fuzzy numbers, such option does not exist. The efficiency of TrOFN also results from the possibility to assess the acceptance level comprehensible for the experts.

The obtained results, performed in a presented case study, illustrate the efficiency of SAW method in case of potential debtors appraisal in case when the order scale is determined by TrOFNs. Further research should focus on approximation of the acceptance level or finding another reliable method of establishing it.

Another, independent direction of research ought to be a way to standardize implemented template based on experts preferences. Possible approaches include the use of electronic negotiation systems as well as implementation of extended behavioral finances.

In view of a progressing computerization and development of IT techniques and models, a question sometimes arises whether it is reasonable to focus on experts' knowledge and its utilization when machines can define and perceive the economic reality almost as well as humans. The clue of the answer can be found in a linguistic expression used in a sentence of doubt, namely, "almost," which is one of those soft expression difficult to quantify. The authors believe that as long as banks use their experts-members of Credit Committee- the answer to this question is positive and that this way the managing board recognizes the efficiency of experts' knowledge, experience and preferences, and therefore the research should be continued.

Author Contributions: Conceptualization, K.P. and A.W.-W.; methodology, K.P.; validation, A.W.-W.; formal analysis A.W.-W.; writing — original draft preparation, K.P. and A.W.-W. All authors have read and agreed to the published version of the manuscript.

Funding: This research received no external funding.

Institutional Review Board Statement: Not applicable.

Informed Consent Statement: Not applicable.

Data Availability Statement: The data presented in this study are available on request from the corresponding author. The data are not publicly available due to bank data confidentiality. 
Acknowledgments: The authors are very grateful to the editor and to the anonymous reviewers for their insightful and constructive comments and suggestions. Using these comments allowed us to improve this article.

Conflicts of Interest: The authors declare no conflict of interest.

\section{References}

1. Kosiński, W. On fuzzy number calculus. Int. J. Appl. Math. Comput. Sci. 2006, 16, 51-57.

2. Piasecki, K. Revision of the Kosiński's Theory of Ordered Fuzzy Numbers. Axioms 2018, 7, 16. [CrossRef]

3. Zadeh, L.A. Fuzzy sets. Inf. Control. 1965, 8, 338-353. [CrossRef]

4. Zadeh, L.A. Fuzzy sets as a basis for a theory of possibility. Fuzzy Sets Syst. 1999, 100, 9-34. [CrossRef]

5. Baldwin, J.F.; Guild, N.C.F. Comparison of fuzzy sets on the same decision space. Fuzzy Sets Syst. 1979, 2, 213-231. [CrossRef]

6. Dubois, D.; Prade, H. A review of fuzzy set aggregation connectives. Inf. Sci. 1985, 36, 85-121. [CrossRef]

7. Dubois, D.; Prade, H. Fuzzy sets, probability and measurement. Eur. J. Oper. Res. 1989, 40, 135-154. [CrossRef]

8. Dubois, D.; Prade, H. Gradualness, uncertainty and bipolarity: Making sense of fuzzy sets. Fuzzy Sets Syst. 2012, 192, 3-24. [CrossRef]

9. Wang, W.J. New similarity measures on fuzzy sets and rough sets. Fuzzy Sets Syst. 1997, 20, 305-309. [CrossRef]

10. Kangari, R.; Riggs, L.S. Construction risk assessment by linguistics. IEEE Trans. Eng. Manag. 1989, 36, 126-131. [CrossRef]

11. Xiwei, W.; Stößlein, M.; Kan, W. Designing knowledge chain networks in China-A proposal for a risk management system using linguistic decision making. Technol. Forecast. Soc. Chang. 2010, 77, 902-915. [CrossRef]

12. Darwis, N.R.; Abdelghany, A.S. A Fuzzy Logic Model for Credit Risk Rating of Egyptian Commercial Banks. Int. J. Inf. Secur. 2016, 14, 11-18.

13. Yazdani, H.; Kwasnicka, H. Fuzzy Classification Method in Credit Risk. In Computational Collective Intelligence. Technologies and Applications. ICCCI 2012. Lecture Notes in Computer Science 7653; Nguyen, N.T., Hoang, K., Jędrzejowicz, P., Eds.; Springer: Berlin/Heidelberg, Germany, 2012.

14. Facchinetti, G.; Bordoni, S.; Mastroleo, G. Bank Creditworthiness Using Fuzzy Systems: A Comparison with a Classical Analysis Approach. In Soft Computing for Risk Evaluation and Management. Studies in Fuzziness and Soft Computing, 76; Ruan, D., Kacprzyk, J., Fedrizzi, M., Eds.; Physica: Heidelberg, Germany, 2001.

15. Mrkalj, M. Introduction of New Fuzzy Methods in Credit Risk Management. In Decision Making and Soft Computing; World Scientific: Singapore, 2014; pp. 620-624. [CrossRef]

16. Pourdarab, S.; Nadali, A.; Nosratabadi, H.E. A Hybrid Method for Credit Risk Assessment of Bank Customers. Int. J. Trade Econ. Financ. 2011, 2, 125-130. [CrossRef]

17. Asset, D. Credit Risk Assessment by Means of Fuzzy Logic Prediction. JMEST 2015, 2, 902-904.

18. Kacprzyk, J.; Fedrizzi, M.; Nurmi, H. Fuzzy Logic with Linguistic Quantifiers in Group Decision Making. In An Introduction to Fuzzy Logic Applications in Intelligent Systems. Springer International Series in Engineering and Computer Science (Knowledge Representation, Learning and Expert Systems); Yager, R.R., Zadeh, L.A., Eds.; Springer: Boston, MA, USA, 1992.

19. Mezei, J.; Byanjankar, A.; Heikkila, M. Credit Risk Evaluation in Peer-to-Peer Lending with Linguistic Data Transformation and Supervised Learning. In Proceedings of the 51st Hawaii International Conference on System Sciences, Big Island, HI, USA, 3-6 January 2018.

20. Cheng, M.-Y.; Hoang, N.-D. Evaluating Contractor Financial Status Using a Hybrid Fuzzy Instance Based Classifier: Case Study in the Construction Industry. IEEE Trans. Eng. Manag. 2015, 62, 184-192. [CrossRef]

21. Łukasiewicz, J. Interpretacja Liczbowa Teorii Zdań, Ruch Filozoficzny (A Numerical Interpretation of the Theory of Propositions). In Jan Łukasiewicz_-Selected Works; Borkowski, L., Ed.; North-Holland, Amsterdam, Polish Scientific Publishers: Warsaw, Poland, 1970; Volume 7, pp. 92-93.

22. Dubois, D.; Prade, H. Fuzzy real algebra: Some results. Fuzzy Sets Syst. 1997, 2, 327-348. [CrossRef]

23. Kosi\#x144;ski, W.; Prokopowicz, P.; Ślęzak, D. Drawback of Fuzzy Arithmetics-New Intuitions and Propositions. In Methods of Artificial Intelligence; Burczyński, T., Cholewa, W., Moczulski, W., Eds.; Silesian University of Technology: Gliwice, Poland, 2002; pp. 231-237.

24. Prokopowicz, P.; Pedrycz, W. The Directed Compatibility Between Ordered Fuzzy Numbers-A Base Tool for a Direction Sensitive Fuzzy Information Processing. Artif. Intell. Soft. Comput. 2015, 9119, 249-259. [CrossRef]

25. Prokopowicz, P. The Directed Inference for the Kosinski's Fuzzy Number Model. In Advances in Intelligent Systems and Computing, Proceedings of the 2nd International Afro-European Conference for Industrial Advancement (AECIA 2015), Villejuif, France, 9-11 September 2015; Abraham, A., Wegrzyn-Wolska, K., Hassanien, A., Snasel, V., Alimi, A., Eds.; Springer: Cham, Switzerland, 2016; Volume 427. [CrossRef]

26. Piasecki, K. Relation "Greater than or Equal to" between Ordered Fuzzy Numbers. Appl. Syst. Innov. 2019, 2, 26. [CrossRef]

27. Piasecki, K.; Łyczkowska-Hanćkowiak, A.; Wójcicka-Wójtowicz, A. The Relation "Greater than or Equal to" for Trapezoidal Ordered Fuzzy Numbers. In Applied System Innovation, Proceedings of the 37th International Conference on Mathematical Methods in Economics 2019, České Budějovice, Czech Republic, 11-13 September 2019; Houda, M., Remeš, R., Eds.; University of South Bohemia in České Budějovice, Faculty of Economics: České Budějovice, Czech Republic, 2019; pp. 61-66. 
28. Prokopowicz, P.; Czerniak, J.; Mikołajewski, D.; Apiecionek, Ł.; Slezak, D. Theory and Applications of Ordered Fuzzy Number: A Tribute to Professor Witold Kosiński. In Studies in Fuzziness and Soft Computing; Springer: Berlin/Heidelberg, Germany, 2017; Volume 356.

29. Herrera, F.; Herrera-Viedma, E. Linguistic decision analysis: Steps for solving decision problems under linguistic information. Fuzzy Sets Syst. 2000, 115, 67-82. [CrossRef]

30. Zadeh, L.A. Toward a theory of fuzzy information granulation and its centrality in human reasoning and fuzzy logic. Fuzzy Sets Syst. 1997, 90, 111-127. [CrossRef]

31. Yao, Y.Y. Granular computing. Comput. Sci. 2004, 31, 1-5.

32. Piasecki, K.; Roszkowska, E. On Application of Ordered Fuzzy Numbers in Ranking Linguistically Evaluated Negotiation Offers. Adv. Fuzzy Syst. 2018, 2018, 1569860. [CrossRef]

33. Zadeh, L.A. The concept of a linguistic variable and its application to approximate reasoning, Part I. Information linguistic variable. Expert Syst. Appl. 1975, 36, 3483-3488.

34. Zadeh, L.A. The concept of a linguistic variable and its application to approximate reasoning, Part II. Inf. Sci. 1975, 8, 301-357. [CrossRef]

35. Zadeh, L.A. The concept of a linguistic variable and its application to approximate reasoning, Part III. Inf. Sci. 1975, 9, 43-80. [CrossRef]

36. Herrera, F.; Alonso, S.; Chiclana, F.; Herrera-Viedma, E. Computing with words in decision making: Foundations, trends and prospects. Fuzzy Optim. Decis. Mak. 2009, 8, 337-364. [CrossRef]

37. Martınez, L.; Ruan, D.; Herrera, F. Computing with words in decision support systems: An overview on models and applications. Int. J. Comput. Int. Syst. 2010, 3, 382-395. [CrossRef]

38. Hwang, C.L.; Yoon, K. Multiple Attribute Decision Making. Methods and Applications. In Lecture Notes in Economics and Mathematical Systems; Springer: Berlin/Heidelberg, Germany, 1981. [CrossRef]

39. Piasecki, K.; Roszkowska, E.; Łyczkowska-Hanćkowiak, A. Impact of the Orientation of the Ordered Fuzzy Assessment on the Simple Additive Weighted Method. Symmetry 2019, 11, 1104. [CrossRef]

40. Mardani, A.; Jusoh, A.; Zavadskas, E.K. Fuzzy multiple criteria decision-making techniques and applications-Two decades review from 1994 to 2014. Expert Syst. Appl. 2015, 42, 4126-4148. [CrossRef]

41. Edwards, W. How to Use Multiattribute Utility Measurement for Social Decisionmaking. IEEE Trans. Syst. Man Cybern. 1977, 7, 326-340. [CrossRef]

42. Chou, S.; Chang, Y. A decision support system for supplier selection based on a strategy-aligned fuzzy SMART approach. Expert Syst. Appl. 2008, 34, 2241-2253. [CrossRef]

43. Roszkowska, E.; Kacprzak, D. The fuzzy saw and fuzzy TOPSIS procedures based on ordered fuzzy numbers. Inf. Sci. 2016, 369, 564-584. [CrossRef]

44. Mays, E. (Ed.) Handbook of Credit Scoring; Glenlake Publishing: Chicago, IL, USA, 2001.

45. Anderson, R. The Credit Scoring Toolkit; Oxford Press: Oxford, UK, 2007.

46. Wójcicka-Wójtowicz, A.; Piasecki, K.M. A Scale of Credit Risk Evaluations Assessed by Ordered Fuzzy Numbers. SSRN Electron. J. 2019. [CrossRef]

47. Wójcicka-Wójtowicz, A.; Łyczkowska-Hanćkowiak, A.; Piasecki, K. Application of the SAW Method in Credit Risk Assessment. In Contemporary Trends and Challenges in Finance: Proceedings of the 5th Wroclaw International Conference in Finance; Jajuga, K., Locarek-Junge, H., Orlowski, L.T., Staehr, K., Eds.; Springer: Berlin/Heidelberg, Germany, 2020; pp. 189-205. [CrossRef] 